\title{
Laboratório Transdisciplinar de Cenografia (LTC): Re-desenhando a exposição de estudantes do Brasil na PQ15
}

\author{
Sônia Maria Caldeira Paiva \\ Universidade de Brasília - UnB, Brasília/DF, Brasil \\ E-mail: soniamcpaiva@gmail.com \\ Caio Sato Schwantes \\ Universidade de Brasília - UnB, Brasília/DF, Brasil \\ E-mail: caio.schwantes@gmail.com
}

\section{Resumo}

O Laboratório Transdisciplinar de Cenografia (LTC) foi concebido e fundado na Universidade de Brasília (UnB) em 2010 pela profa. Dra. Sônia Paiva, para participar da Quadrienal de Praga de 2011 - PQ11. O LTC é um laboratório baseado em quatro pilares: Transdisciplinaridade, Diversidade, Colaboração e Economia Criativa. O conceito foi inspirado na compreensão da necessidade de romper com a estrutura disciplinar universitária, para conectar produtores, pensadores, técnicos, cientistas e artistas na realização de projetos inovadores, que possam desencadear transformações culturais, sociais, políticas e humanas. O resultado disso é um olhar colaborativo, multicultural que é compartilhado no Desenho da Cena. A curadoria da Mostra dos Estudantes Brasileiros de Desenho da Cena na Quadrienal de Praga 2015, marcou a metodologia processual do LTC. A exposição, apresentada na PQ15, condensou um trabalho colaborativo com os núcleos de ensino de cenografia brasileiros e explicitou como cada estado e escola operam seus processos criativos. Assim, nosso espaço expositivo apresentou a diversidade cultural brasileira em Praga; nos remeteu a uma cabana - que poderia estar em qualquer lugar, em um estado mutável - e nos convidou a vivenciar os espaços imaginativos de nossos estudantes, levando os visitantes a sonharem com outros territórios em uma abordagem mais atenta e participativa.

Palavras-chave

Laboratório. Transdisciplinaridade.

Cenografia. Quadrienal de Praga. Multiculturalismo.
Abstract

The Stage Design Transdisciplinary Laboratory (LTC in Portuguese) was conceived and founded at the University of Brasilia (UnB) in 2010 by professor Dr. Sônia Paiva, to attend the 2011 Prague Quadrennial - PQ11. LTC is a laboratory based on four pillars: Transdisciplinarity, Diversity, Collaboration and Creative Economy. The concept was inspired with the understanding of need to dismantle the university disciplinary structure, to connect producers, thinkers, technicians, scientists and artists in the realization of innovative projects that can trigger cultural, social, political and human transformations. The result is a collaborative, multicultural look that is shared in Scene Design. The curatorship of the Brazilian Students of Scene Drawing at the Prague Quadrennial 2015 marked the LTC's methodology. The exhibition, presented in PQ15, condensed a collaborative work with the Brazilian scenography teachers centers and explained how each state and school operate their creative processes. Thus, our exhibition space presented the Brazilian cultural diversity in Prague; reminds us of a cabin - which could be anywhere, in a changing state - and invited us to experience our students' imaginative spaces, prompting visitors to dream of other territories in a more attentive and participatory approach.

Keywords

Laboratory. Transdisciplinarity. Scenography. Prague Quadrennial. Multiculturalism. 


\section{Laboratório Transdisciplinar} de Cenografia (LTC)

Você só pode se encontrar se estiver perdido. Essa é a primeira regra do labirinto. Se você pensa que está perdido... é porque você está procurando por algo. E se você está procurando por algo... é porque você sabe o que quer! Se você sabe o que quer... você está à frente e sendo seguido por um bando de loucos ${ }^{1}$

O Laboratório Transdisciplinar de Cenografia (LTC) é um Programa de Extensão de Ação Contínua (PEAC), organizado e coordenado pela Profa. Dra. Sônia Paiva, no Instituto de Artes da Universidade de Brasília - UnB. O grupo foi criado em 2010 como um Projeto Interdisciplinar de Extensão, para participar da Mostra das Escolas Brasileiras de Cenografia na Quadrienal de Praga em 2011 - MEPQ11.

$\mathrm{Na}$ ocasião, Fausto Viana, o curador da Mostra das Escolas Brasileiras dava prosseguimento ao trabalho de abertura da Quadrienal, iniciado na edição de 2007 por Lidia Kosovski, convidando centros de ensino para além da região sudeste, que historicamente dominou a cena do festival desde sua criação. Segundo ele "a preocupação com a diversidade do país foi o fio condutor do processo" (VIANA, 2011, p. 21). Foram então convidados para enviar projetos, a Universidade Federal do Rio Grande do Sul (sob a representação de Marco Fronckowiak), a Universidade de Brasília (na figura de Sônia Paiva), a Universidade Federal do Rio Grande do Norte (por meio de Sávio Araújo), a Universidade de Campinas (com Márcio Tadeu e Helô Cardoso), o Ateliê Lu Grecco (coordenado por Luciene Grecco) - e a SP Escola de Teatro - representado por Adriana Vaz Ramos (VIANA, 2011. p. 21-22).

$\mathrm{Na}$ UnB, foram convocados, sob orientação de Sônia Paiva, estudantes das diversas áreas do conhecimento para formarem grupos interdisciplinares que produziram projetos para concorrerem na seletiva na Universidade de São Paulo - USP. Ao total, foram dezessete discentes dos cursos de Artes Cênicas, Arquitetura, Artes Plásticas, Comunicação Social, Audiovisual e Desenho Industrial que compuseram cinco grupos. Esses grupos concorreram com sete trabalhos (nas áreas de figurino e cenografia), dos quais quatro foram selecionados para compor a MEPQ11, sendo o projeto "A Terceira Margem do Rio" selecionado como melhor trabalho da mostra seletiva e a discente Julia Gonzales escolhida para o prêmio Funarte de melhor aluna. Nessa edição da Quadrienal, o Brasil ganhou a Triga de Ouro (Golden Triga), prêmio máximo do evento, que destacou o conjunto de cenógrafos brasileiros como o melhor da edição.

\section{Figura 1 - Estande da Mostra das Escolas Brasileiras de Cenografia em Praga.}

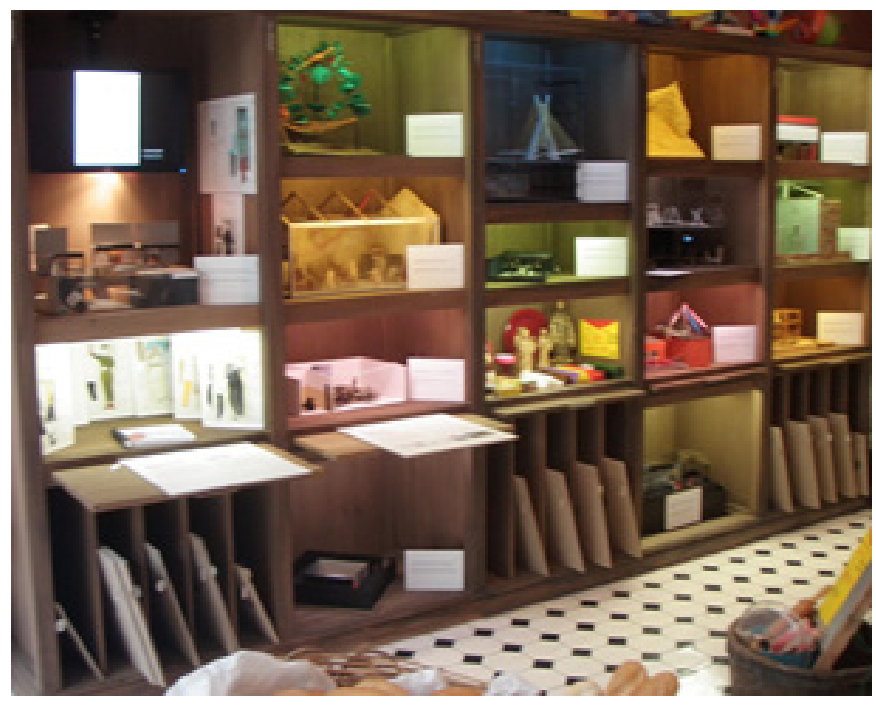

Fonte: Arquivo LTC, 2011. 
Figura 2 - Detalhes dos projetos do LTC.
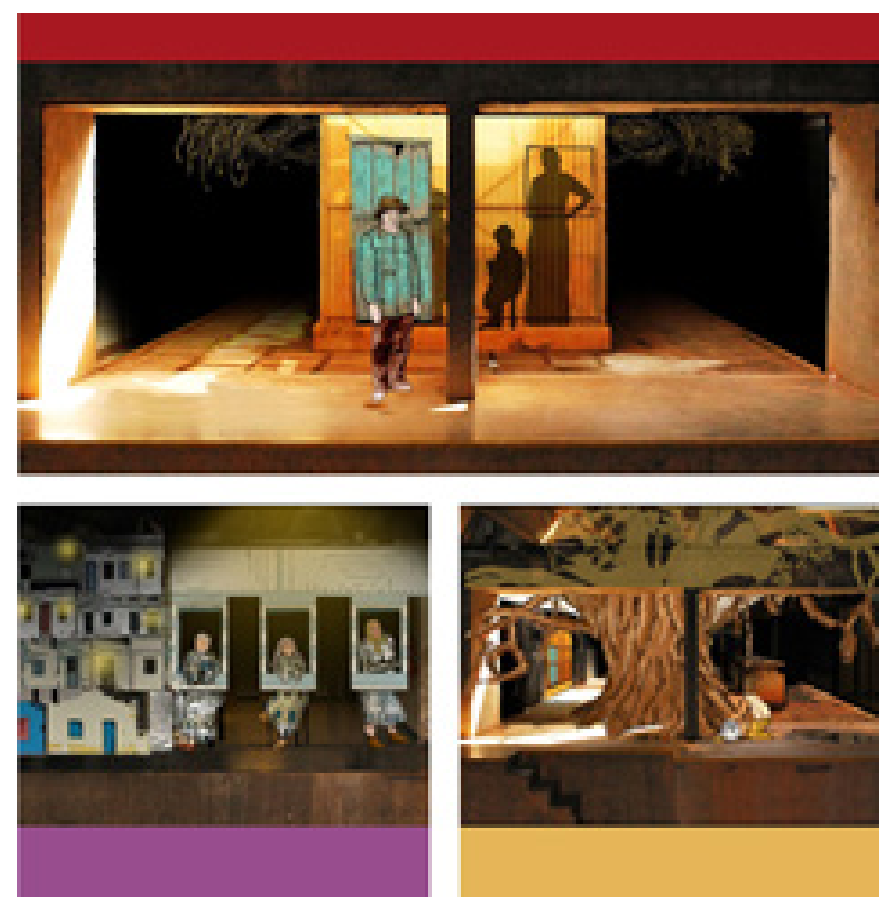

Fonte: Arquivo LTC, 2011.

Após o retorno de Praga, o Laboratório continuou produzindo, pesquisando e se engajando em ações múltiplas na UnB e fora dela. Para o doutorado de Sônia Paiva, o Projeto de Extensão Interdisciplinar foi transformado em Programa de Extensão de Ação Continuada - PEAC e renomeado como Laboratório Transdisciplinar de Cenografia. Visando novas formas de colaboração, agregamos aos campos com os quais já trabalhávamos novas áreas de conhecimento - como Música, Química, Geologia, Computação e outros - com intuito de criar projetos de maior impacto e abrangência. No LTC, o processo de reconexão dessas várias áreas do conhecimento foi impulsionado pelo desejo individual de pesquisar e criar, percebendo a inteligência múltipla dos grupos, para o desenvolvimento de uma poética multicultural comum.

\section{A criação de um laboratório - início do labirinto}

Este laboratório foi criado como uma reação natural ao sistema de ensino disciplinar estabelecido nas escolas de artes cênicas e nas universidades brasileiras em geral. A exemplo disso, o sistema de ensino do Departamento de Artes Cênicas da UnB é orientado para o Bacharelado de Interpretação - com foco na formação de atores e performers - e para a Licenciatura em Teatro - que visa a formação de professores da educação básica. Este direcionamento curricular, muitas vezes desconsidera como parte da formação o fazer teatral vindo de outras áreas - como as artes plásticas, novas mídias, iluminação, sonoplastia, comunicação e design gráfico - que integram e compõem o desenho da cena como um todo. O sistema educacional brasileiro, ainda é compartimentado em cursos e disciplinas, pouquíssimo interligados, de modo a empobrecer esse conhecimento do teatro.

Ao buscar a religação entre esses vários cursos e disciplinas, o LTC compreende suas ações para além do fazer cenográfico, seu fazer é mais afinado com o conceito híbrido de Desenho da Cena proposto por Praga.

O Desenho da Cena é um desenvolvimento natural do campo da cenografia. Aby Cohen explica que o termo Desenho da Cena parte da tradução de Performance Design, usado amplamente por especialistas de todo o globo que estão em consonância com as mais recentes investigações relacionadas às práticas cenográficas. Segundo ela:

O conceito desenho da cena emerge, portanto, para reforçar a noção de hibridismo como qualidade da produção do artista cenógrafo ou designer de cena que atua no ENTRE. Hibridismo como um leque que reúne um amplo espectro de modalidades artísticas visuais, sensoriais, e por vezes também arquitetônicas, que são a todo instante percebidas e 
assimiladas pelo artista. Refere-se sobretudo à produção do artista cujo interesse reside tanto na multidisciplinaridade como na transitoriedade entre as linguagens aqui abordadas. (COHEN, 2015, p. 10).

Para além dessa situação do hibridismo apontada por Cohen (2015), o Laboratório pensa o Desenho da Cena para além das fronteiras disciplinares, se esbarrando nos conceitos de Arte e Vida.

Paiva (2016) aponta que:

O Desenho da Cena é estabelecido pela interdependência do espaço com o humano. Dessa forma, minhas preocupações com a pedagogia que desenvolvo passam, principalmente, pelo desenvolvimento das relações entre as pessoas e $o$ ambiente que as cerca e vão para além do palco teatral, estendendo-se para a diversidade da vida real. (PAIVA, 2016, p. 49, grifo nosso).

\section{Sobre a prática do LTC}

O LTC é um lugar onde nós experienciamos a abordagem da Cenografia como Desenho da Cena, na formação acadêmica. O objetivo é difundir a tese de que o ensino do Desenho da Cena deve se basear na realização de projetos que interajam os conhecimentos híbridos produzidos na universidade, formando equipes multidisciplinares para ações transdisciplinares. É uma maneira de experimentar a academia de forma holística, realizando projetos culturais que podem fortalecer a mobilização social e política (PAIVA, 2016).

Ubiratan D’Ambrósio, professor emérito da Universidade Estadual de Campinas - Unicamp, reconhecido sobretudo por sua pesquisa no campo da etnomatemática ${ }^{2}$, explica a base para a transdisciplinaridade:

2 Etnomatemática é o campo que estuda as formas e técnicas culturais de contar e conhecer o mundo.
O essencial da Transdisciplinaridade reside na postura de reconhecimento onde não há espaço e nem tempo culturais privilegiados que permitam julgar e hierarquizar como mais corretos - ou mais certos ou mais verdadeiros - os diversos complexos de explicações e de convivência com a realidade. A transdisciplinaridade repousa sobre uma atitude aberta, de respeito mútuo e mesmo de humildade com relação a mitos, religiões e sistemas de explicações e de conhecimentos, rejeitando qualquer tipo de arrogância ou prepotência. A transdisciplinaridade é transcultural na sua essência. (D’AMBROSIO, 1997, p.79-80).

Como muitos pensadores atuais, nós do LTC trabalhamos na tarefa de contribuir para a construção de uma sociedade justa e um sistema educacional que leve em consideração o desenvolvimento do indivíduo e as relações entre eles, entre os grupos e as nações.

Figura 3 - LTC no Parque de Produções, estudo da organização espacial da MEPQ15 em Praga.

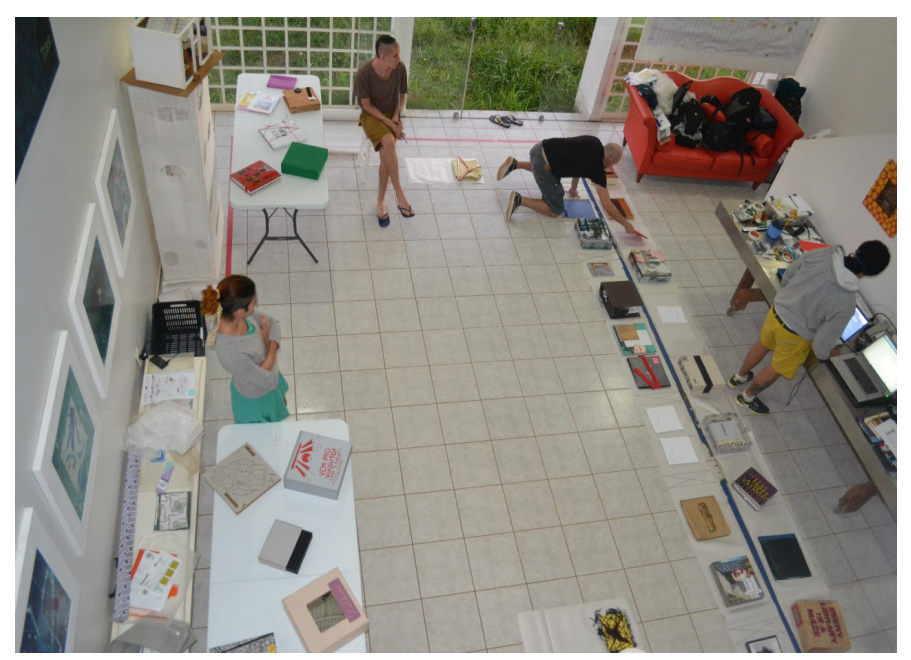

Fonte: Arquivo pessoal de Sônia Paiva, 2014.

Entre 2012 e 2016, o LTC foi o locus de observação da tese de doutorado de Sônia Paiva. A visão pessoal de sua poética presente na 
abordagem transdisciplinar de seu mestrado, realizado entre 2003 e 2005, transforma-se na formação de um grupo no qual cada membro reflete uma face de sua expressão multifacetada, em que os projetos são os fios condutores das ações ${ }^{3}$.

Desse modo, o LTC foi criado para formar um ecossistema de conhecimento multicultural através das artes, ciências, educação, ecologia e humanidades. Abrange a diversidade como um terreno fértil para a criação de múltiplos projetos; aproveita os recursos humanos disponíveis na universidade em ações colaborativas e inclusivas e utiliza várias tecnologias - manual, mecânica e digital - combinando as ações analógicas aos novos canais de criação e comunicação em rede.

Buscamos principalmente um processo iterativo entre diferentes sujeitos, focando na construção de um terreno comum por meio das conexões entre os indivíduos. É na interseção entre arte e realidade, criação e realização, que florescem as demandas de participação de outras áreas da estrutura produtiva.

Edgar Morin aponta a necessidade de romper com a fragmentação do pensamento.

Torna-se necessário, portanto, promover a circulação de saberes que nos motivem a romper com a fragmentação do conhecimento que nosso modo de viver ocasiona. Trata-se da oportunidade de conduzir o homem a encontro consigo mesmo e em todas as suas dimensões, ou seja, da oportunidade de celebrar o encontro entre pessoa e natureza como expressões de uma única manifestação da vida, sem dicotomias e sem espaço para um existir predatório e desagregador. (MORIN, 2013, p. 11).
Como solução dessa fragmentação, o autor propõe o "pensamento complexo" e o opõe aos pontos de vista simplificadores.

A complexidade situa-se num ponto de partida para uma ação mais rica, menos mutiladora. Acredito profundamente que quanto menos um pensamento for mutilador, menos ele mutilou os humanos. É preciso lembrar-se dos estragos que os pontos de vista simplificadores têm feito, não apenas no mundo intelectual, mas na vida. MiIhões de seres sofrem o resultado dos efeitos do pensamento fragmentado e unidimensional. (MORIN, 2015, p. 83).

\section{_ Seletiva - mostra dos estudantes brasileiros para a Quadrienal de Praga}

Sônia Paiva foi nomeada, em 2014, curadora da Mostra dos Estudantes Brasileiros de Desenho da Cena da Quadrienal de Praga 2015 - MEPQ15, participando da representação brasileira, tendo como curador geral Ronald Teixeira. Nessa edição, Teixeira compartilhou a curadoria da Mostra dos Países e Regiões com Doris Rollemberg e Rosane Muniz. A PQ15 contou com a temática SharedSpace: Music Weather Politics ${ }^{4}$, da qual a delegação brasileira retirou seu conceito norteador: Política.

Segundo Doris Rollemberg, no catálogo organizado por Rosane Muniz da mostra brasileira, Brasil tudo por recomeçar:

Corroboramos com a tese apresentada pelo conceito norteador Política que aponta o papel fundamental do designer como responsável pela (re)definição do espaço da cena como um lugar de encontros e conflitos. Nesse sentido, reconhecemos

3 Por meio da leitura da dissertação de Paiva "A encenação pictórica: uma abordagem transdisciplinar". (2006) e também de sua tese "O Laboratório Transdisciplinar de Cenografia (LTC): lócus do espaço e desenho da cena no Brasil" (2016), é possível compreender a transição da poética pessoal para uma poética coletiva. 4 Este tema foi traduzido como EspaçoCompartilhado: Sonori-
dade Atmosfera Política pela curadoria. 
o designer não apenas como o titular do palco, aquele que antevê e revela o traçado do espaço. Ele deve ser [...] aquele que igualmente antevê e faz ver a ampliação dos limites físicos do espaço. (MUNIZ, 2015, p. 26)

A Mostra dos Estudantes BRASIL: LABirintos Compartilhados trouxe como proposta curatorial a ampliação do mapeamento dos espaços de ensino da cenografia no Brasil e o compartilhamento dos processos de criação do desenho da cena via plataforma virtual. Uma das principais características que é possível conferir no projeto curatorial, além da ampla convocação a todos os centros brasileiros de ensino da cena, é a colaboração perpassando todo o processo:

Nosso maior desejo é contribuir com os centros de educação que questionam, desafiam e levam adiante a discussão do ensino da cenografia como um campo expandido que abrange diversas linguagens artísticas, de modo que esperamos o amplo engajamento dos docentes para colaborarem conosco no debate sobre espaço compartilhado ${ }^{5}$.

O processo, que teve início em março de 2014, envolveu 20 unidades educacionais de 4 regiões brasileiras (Sul, Sudeste, Centro-Oeste e Nordeste $)^{6}$, formando um quadro representativo da diversidade das instituições brasileiras de cenografia.

5 Disponível em: <https://brasillabirintoscompartilhados.files. wordpress.com/2014/05/projeto-curatorial.pdf>. Acesso em: 23 nov. 2019.

6 Este é o número final de instituições que participaram do processo, contudo, destas 20 unidades educacionais, apenas 15 enviaram trabalhos para participar da mostra seletiva.
Figura 4 - Júri composto por Ronald Teixeira, Lu Bueno e João Irênio Maia avaliando os trabalhos na Seletiva para a Quadrienal de Praga 2015, Brasília.

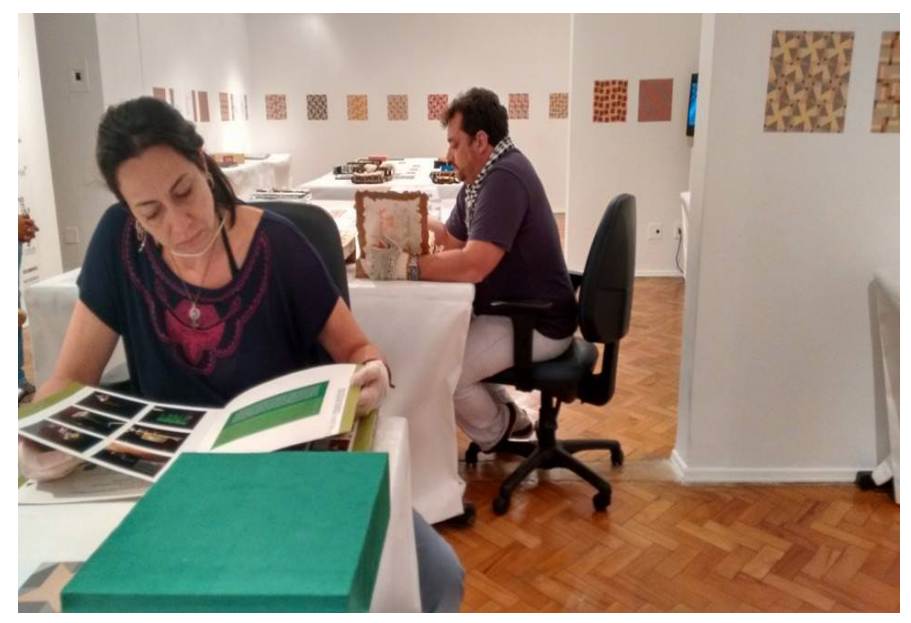

Fonte: Acervo LTC, 2015.

O júri, composto por figuras importantes da Cenografia Brasileira e convidado pela curadora, encontrou uma mostra em Brasília elaborada para receber e expor o maior número possível de projetos dos estudantes - a Seletiva apresentou projetos de alto nível provenientes de diferentes grupos de ensino, tendo como saldo positivo o mapeamento e a comunicação entre esses grupos. Durante a exposição foi ressaltada a importância do trabalho desenvolvido em sala de aula e levado para a plataforma digital.

\section{Chamada nacional: um convite aos labirintos}

BRASIL: LABirintos Compartilhados é o título e o conceito que visa incentivar a reflexão sobre a multiplicidade do fazer cênico e proporcionar o compartilhamento de experiências, descobertas e entendimentos em sua origem, nos laboratórios de ensino. Isso é sugerido por uma das etimologias da palavra labirinto, que deriva de "labor" (trabalho) e "intus" (interior ou espaço fechado). Os pesquisadores e estudantes brasileiros do campo foram convidados a expor suas diferentes abordagens e peculiaridades regionais visando a possibilidade 
da construção de uma unidade nacional singular a partir das suas particularidades (PAIVA, 2015).

A partir das diretrizes da chamada nacional, os projetos foram organizados em cadernos, fotos e vídeos - álbuns cartográficos - nos quais foram inseridos os trabalhos cenográficos das diferentes escolas, priorizando o registro dos processos e rotas das ações que criaram o desenho e o espaço da cena. Sugeriu-se às escolas buscar referências territoriais decorrentes de múltiplos modos expressivos: contos, poemas, textos dramatúrgicos, imagens e eventos factuais no território, a fim de investigar e interpretar de maneira livre o tema Política.

\section{Um site para diálogo nacional entre os núcleos de ensino}

Para esta edição, construímos um projeto de diálogo a partir de ações comunicacionais, com o objetivo de aumentar o número de escolas participantes e a contribuição das regiões geopolíticas brasileiras na Quadrienal de Praga. Assim, foi criado o site https://brasillabirintoscompartilhados. wordpress.com/, vinculado ao e-mail mepq15@ gmail.com, com o objetivo de mapear os centros de ensino, orientar as etapas de inscrição e produção dos projetos desenvolvidos por professores e estudantes brasileiros e estimular a troca de conteúdos entre os educadores, por meio de textos e debates, possibilitando intensa comunicação entre os centros de ensino durante o processo pedagógico.

Pela primeira vez, a exposição para selecionar os projetos de estudantes brasileiros de cenografia a serem apresentados na Quadrienal de Praga foi realizada - fora do eixo Rio-São Paulo - em Brasília, na Casa da Cultura da América Latina (CAL/UnB), e convertida em um evento nacional de 5 dias. A transformação dessa etapa em um evento nacional só foi possível graças ao apoio da UnB e ao trabalho voluntário do LTC. A curadoria dividiu o evento em: exibição de todos os trabalhos enviados para Brasília; apreciação do júri e divulgação do resultado; mesas redondas com professores e profissionais brasileiros convidados para debater - os critérios utilizados pelo júri na seleção dos projetos, o ensino da Cenografia em vários níveis educacionais e o Desenho da Cena no Brasil; oficinas de iluminação, cenografia e maquiagem com os professores convidados; venda de livros autorais relacionados à cenografia e publicados por professores brasileiros; e a apresentação de peça teatral de diplomação da UnB.

Figura 5 - Abertura da Seletiva para a Quadrienal de Praga 2015 na Casa da Cultura da América Latina -

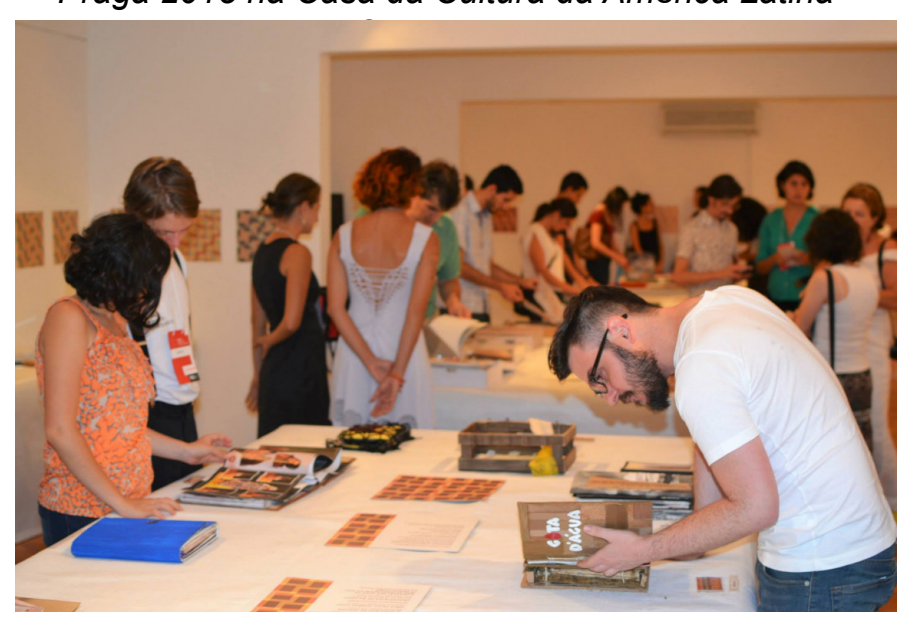

Fonte: Acervo Helano Stuckert, 2015.

A Universidade de Brasília ofereceu o espaço da CAL e recursos para produção de material gráfico. Para financiar a exposição em Brasília, o LTC também realizou financiamento coletivo, organizou a Festa Tcheca e atraiu alguns patrocinadores locais. Também contamos com recursos públicos estaduais (FAC/DF) e federais (Funarte) para levarmos os trabalhos e a equipe para a Quadrienal de Praga.

Esse levantamento de verba, organizado pelo Laboratório, foi fundamental para a realização do evento em Brasília, já que este não era previsto na programação da curadoria nacional. Sendo somente programado para os recursos da Funarte (tradicional patrocinadora da delegação brasileira na Quadrienal), o envio dos trabalhos e o custeio de uma pequena equipe, para montagem do stand, na PQ15.

O LTC, estabelecido no Parque de Produ- 
ções de Sônia Paiva, ensaiou e planejou durante um ano e meio todo o evento, permitindo que um grupo de alunos universitários estivessem prontos e aptos a montarem a exposição e atenderem ao público durante a exposição na PQ15. Dessa forma, uma de nossas principais metas era levar os 12 integrantes do grupo para o evento em Praga.

\section{Identidade visual do Brasil: LABirintos compartilhados}

O design gráfico do BRASIL: LABirintos compartilhados $^{7}$ foi feito a partir de um jogo digital - disponível no site - criado para a construção de uma base modular colaborativa. Esta base foi utilizada na construção da identidade visual em várias etapas do projeto curatorial: como símbolo identificador de cada escola em Brasília e de cada trabalho em Praga. Os símbolos criados pelas escolas formaram juntos um tecido, como um patchwork, que cobria todo o espaço do stand como a cobertura de uma tenda (vide Figura 8).

Cada centro de ensino criou um símbolo para sua escola, composto por três linhas traçadas em uma grade quadrada (vide Figura 6) - representando um palco vazio - em um plano demarcado por 16 pontos.

Figura 6 - O jogo digital, disponibilizado no site, para criar o visual do BRASIL: LABirintos compartilhados.
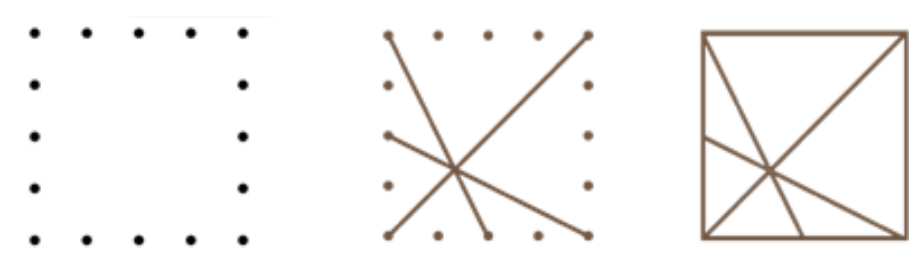

Fonte: Acervo LTC, 2015.

$7 \mathrm{Em}$ 2017, a identidade visual do BRASIL: LABirintos compartilhados foi selecionada para compor a $12^{\mathrm{a}}$ Bienal do Design Gráfico. Disponível em <http://12.bienaladg.org.br/>. Acesso em: 16 nov. 2019.
Em seguida, cada escola preencheu o seu símbolo com as cores terrosas da paleta fornecida pela curadoria (Fig. 7), finalizando a identificação das instituições (Fig. 8).

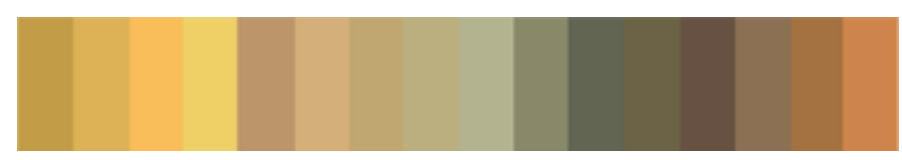

Fonte: Acervo LTC, 2015.

Figura 8 - Marcas finais criadas por cada um dos núcleos de ensino a partir do grid com a paleta de cor.

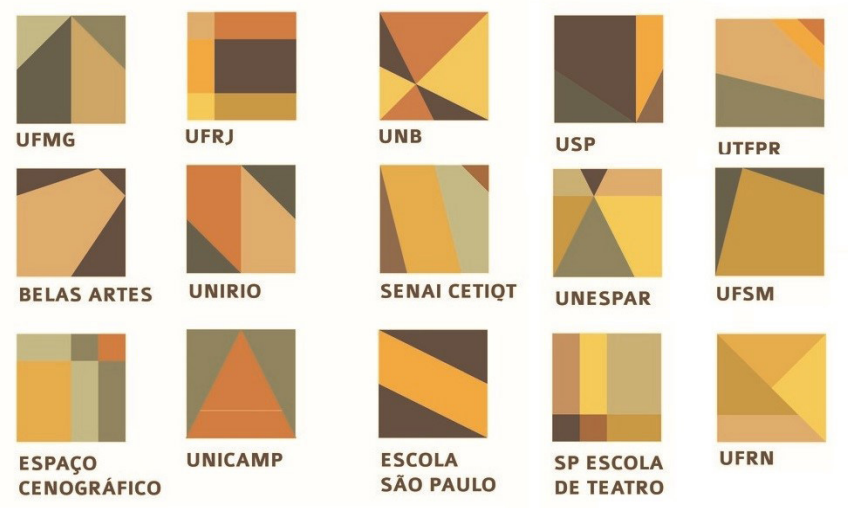

Fonte: Acervo LTC, 2015.

\section{- Mostra dos estudantes na Quadrienal de Praga 2015}

Na Quadrienal de Praga de 2015, os símbolos criados por cada escola compunham um grande patchwork - eram pedaços de um quebra-cabeça reunidos na sala de exposições. Essa escolha de utilizá-los para integrar o espaço expositivo permitiu que cada parte fosse reconhecida no processo como uma peça fundamental do resultado coletivo e único.

A exposição foi instalada no Kafka's House, no centro de Praga, com o formato de uma tenda - um espaço volante - onde se apresentaram os álbuns cartográficos das escolas. As peças eram dispostas de modo a instigar o observador a sentar-se e ler. 
Figura 9 - Exposição BRASIL: LABirintos Compartilhados na PQ15, no prédio Kafka's House, Praga.

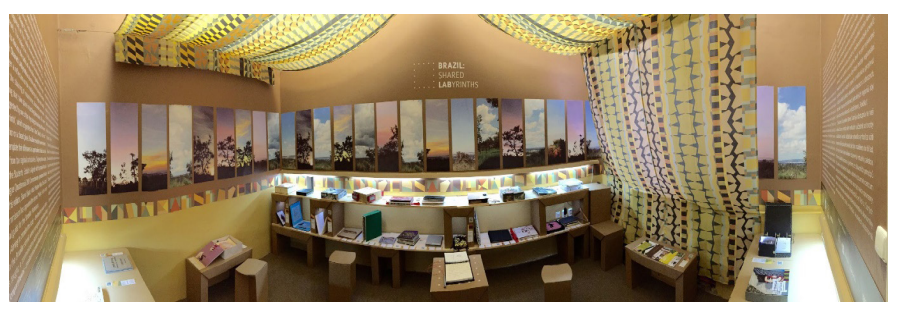

Fonte: Acervo LTC, 2015.

A exposição mostrada em Praga condensou o processo de pensamento e a construção da cena e buscou explicar como cada centro de ensino opera. No Catálogo do BRASIL: LABirintos compartilhados, é possível esmiuçar cada um dos 33 trabalhos selecionados que compuseram a Mostra em Praga (além de ser possível conferir brevemente os 68 projetos enviados para a seletiva). Ainda no catálogo, cada unidade educacional teceu um breve texto sobre como se deu a preparação e a confecção dos trabalhos. Vejamos algumas delas:

A Universidade de Brasília, no Centro-Oeste, teve 3 projetos selecionados - Entrevazios, Temos Todas a Mesma História e Caraíba - todos eles envolvidos de certo modo com as relações pessoais (entre sujeitos, sujeito e cidade e sujeito e meio-ambiente). A prática de ensino descrita no catálogo ressalta como se deram as orientações que compuseram grupos transdisciplinares:

Apresentamos narrativas cenográficas resultantes de um processo contínuo de arte e relações, que se dividiu em dois momentos. No primeiro, 35 alunos de 9 diferentes áreas do saber foram preparados pela professora Sônia Paiva e pelo Laboratório Transdisciplinar de Cenografia [...] experienciando o desenho da cena. No segundo, divididos em grupos e focados no tema políticas, os participantes tiveram acompanhamento de professores orientadores e periodicamente com o LTC, o que possibilitou uma mistura de meios e estilos que formou uma trama baseada na busca de conhecimento, na amizade, na troca e na paixão pela arte. (PAIVA, 2015, p. 95).

AUniversidade Tecnológica Federal do Paraná - UTFPR, por sua vez, participou da Quadrienal com o projeto selecionado Sinal Fechado. Os trabalhos enviados para a seletiva foram fruto de uma experimentação que partiu de uma música que serviu como texto base. É interessante notar que foi criado um programa de extensão para a produção dos projetos:

Para a participação na Mostra, foram articulados grupos de trabalho com alunos dos cursos de graduação em Design e em Arquitetura e Urbanismo com alunos do Curso de Especialização em Cenografia da UTFPR, sob a coordenação do Prof. Ismael Scheffler, criando-se o programa de Extensão Desenvolvimento Cenográfico. A partir do tema "Politics", os grupos foram orientados à experimentação corporal do espaço, à explorações bi e tridimensionais, considerando as relações dinâmicas entre formas, objetos e pessoas. Cada grupo escolheu uma música que serviu como texto motor para a criação, resultando em propostas cenográficas que possibilitassem e induzissem interações. (PAIVA, 2015, p. 107).

Noturno e O gol não valeu foram os dois trabaIhos selecionados da Universidade Federal de Minas Gerais - UFMG. Eles foram desenvolvidos em uma disciplina ministrada conjuntamente pelos professoresorientadores:

Os projetos enviados pelos alunos da Universidade Federal de Minas Gerais foram desenvolvidos na disciplina Oficina de

8 Cada um desses textos foi enviado pelas instituições de ensino para integrar o catálogo. Como nenhum deles tem indicação de autoria, atribuímos esta aos Centros Educacionais. 
Cenografia, ministrada pelos professores Cristiano Cezarino, Ed Andrade e Tereza Bruzzi. A disciplina teve como objetivo a abordagem de aspectos conceituais e práticos referentes à cenografia. Os alunos se envolveram no processo de criação de cenografia de montagens existentes na cidade, com trabalhos norteados por noções básicas do processo de concepção e produção do espaço cênico, através de aulas expositivas, discussões, análise de cenografias teatrais, dinâmicas em grupo, participações de convidados nas aulas e orientação dos trabalhos práticos desenvolvidos. (PAIVA, 2015, p. 115).

A UNIRIO - Universidade Federal do Estado do Rio de Janeiro teve os projetos Travellers, Vem pro viaduto, Vão, Cinelândia (1968-2013), Percursos Urbanos e Metamorfose selecionados. De acordo com a descrição no catálogo, o que foi considerado no processo foi a autonomia de criação. Os trabalhos apresentavam influências claras da cidade do Rio de Janeiro, assim como do carnaval.

No exercício de um pensamento crítico e reflexivo para a produção artística e cognitiva, vinculadas às dimensões estéticas e espaciais contemporâneas, os professores e estudantes da Escola de Teatro da UNIRIO vivenciaram a liberdade de criar seus pares ou grupos para 0 desenvolvimento dos projetos, desfrutando de total autonomia intelectual na criação dos cadernos ao longo do ano de 2014. Procurou-se, dessa maneira, assegurar, estimular e capacitar o desenvolvimento de diversos olhares e possibilidades artísticas capazes de compreender, intervir e transformar nossa realidade através da investigação, análise e discussão conceitual da criação de espaços e dispositivos semânticos variados. (PAIVA, 2015, p. 129).
O Espaço Cenográfico de São Paulo apresentou os projetos Cidade Móvel - Volume vivo e Minhocão ap.72 - que recebeu o prêmio de projeto destaque e deu uma passagem para que um de seus integrantes fosse para a Quadrienal de Praga. Os trabalhos do Espaço Cenográfico pensavam ações e intervenções nesse centro urbano denso que é a cidade de São Paulo:

O Espaço Cenográfico é um laboratório permanente de pesquisa na área cenográfica. Todos os projetos, estudos e experiências nele desenvolvidos relacionam-se fortemente com nossa cidade. São desenvolvidos, todo ano, projetos que discutimos políticas teatrais da cidade e a grande maioria dos projetos trabalham a ocupação de espaços na cidade que não foram projetados para teatro. São apropriações, sites específicos e interferências urbanas, que vêm ao encontro aos temas propostos pela $P Q$ e pela curadoria brasileira para a mostra de 2015. (PAIVA, 2015, p. 155).

\section{Conclusão}

A Mostra dos Estudantes na Quadrienal de Praga 2015 foi uma síntese da prática laboratorial desenvolvida por Sônia Paiva que se realizou de modo colaborativo e que constituiu um território que abrigava a diversidade cultural no Brasil:

Aqui a impressão momentânea é de estar em um lugar qualquer, num estado mutável que convida a experienciar o espaço e leva a sonhar com outros territórios de forma mais atenta e participativa. Convidamos o visitante a experimentar um complexo labirinto: o horizonte das paisagens internas brasileiras. (PAIVA, 2015, p. 89).

O (re)desenho da Mostra dos Estudan- 
tes na representação brasileira, que foi proposto por Sônia Paiva, em colaboração com o Laboratório Transdisciplinar de Cenografia, contribuiu na expansão dos núcleos participantes, assim como marcou um movimento de expansão da participação dos centros de ensino, permitindo, assim, uma representação ampla da cenografia brasileira.

O resultado dessa política é o vislumbre do estabelecimento de um fórum perene da pesquisa, relacionamentos e difusão do desenho da cena, com foco em um canal de intercâmbio entre as escolas brasileiras durante os períodos entre as quadrienais. (PAIVA, 2015, p.88).

Continuando a prática de conectar e aproximar os diversos atores da cenografia e do desenho da cena no Brasil a curadoria brasileira da Quadrienal de Praga de 2019, na direção de Aby Cohen, criou o site PQ Brasil https://pqbrasil.org/ que almeja ser um repositório de informações sobre a atuação do Brasil na Quadrienal de Praga.

\section{O LTC na PQ19}

Para essa edição da Quadrienal de Praga, apesar de ter sido questionada sobre a possibilidade de continuar o trabalho curatorial da mostra dos estudantes, em encontro na UNIRIO em 2017, Sonia Paiva expressou sua vontade de apresentar um trabalho autoral do LTC, que vinha sendo desenvolvido pensando na participação no World Stage Design Festival (WSD) em Taipei.

O projeto Drawing Narratives: from sand to light propõe uma atmosfera ritualística para o engajamento da audiência numa vivência performática $\mathrm{e}$ formativa. Consiste numa sobreposição de ações partindo da apresentação de uma antiga tradição - a geometria Sona da cultura Cokwe, no Leste de
Angola - e deslocando-se, por meio de ações lúdicas, para a captura do movimento de luz no espaço. (BEHANCE, 2019).

Em agradecimento pela obra inspiradora de Ubiratan D'Ambrosio, que norteou e fundamentou boa parte do Programa de Extensão de Ação Continuada - o Laboratório Transdisciplinar de Cenografia (LTC), lócus observacional de sua tese de doutorado -, Sonia Paiva enviou um e-mail para D’Ambrosio, com o filme de apresentação do projeto em desenvolvimento ${ }^{9}$, que assim o respondeu:

\begin{abstract}
Prezada Sonia
Que alegria receber um e-mail assim. Que belo projeto. Narrativa é muito mais que o um encadeamento de palavras. É o todo narrando, como você propõe. Muito bom mesmo. Reforça minha convicção que o enfoque transdisciplinar e transcultural é o caminho para conhecimento e comportamento humanos no sentido amplo. (Re: Agradecimento por sua obra inspiradora [Mensagem pessoal]. Mensagem recebida por soniamcpaiva@gmail.com em 09 out. 2016)
\end{abstract}

Dessa forma, o projeto foi retrabalhado para ser apresentado na PQ19, sendo formatado como workshop e renomeado com o título de Drawing Narratives Experience. O projeto foi selecionado para a PQStudio e apresentou 4 seções na Academy of Performing Arts in Prague (DAMU). A recepção de nosso trabalho foi muito positiva e reverberou profundamente naqueles que participaram, a exemplo disso temos o depoimento de Iff Atanasova em 5 de julho, via Facebook, que comentou um pouco sobre a nossa apresentação.

Você sabia que o Brasil atual-

\footnotetext{
9 Disponível em: <https://www.behance.net/gallery/42248335/ Drawing-Narratives-from-sand-to-light-2016>. Acesso em: 20 nov. 2019.
} 
mente não possui um ministério da cultura, devido às políticas de seu atual presidente? Você acredita nisso?! Eu acredito. Essa galera veio até Praga, sem serem apoiados pelo seu estado, para compartilharem cultura, arte e criar pensamentos. O trabalho deles como Laboratório Transdisciplinar de Cenografia, liderado por Sonia Paiva, é fantástico. Por quê? Porque eles vão além do visível e não há violência. Qualquer um pode fazer isso. Visitei o workshop no PQ 2019 e saí de lá com um pensamento genuíno, comparando a política de merda do meu país em relação à cultura com a deles: somos todos iguais. NÓS podemos fazer isso? Esse não é o ponto, apenas FAÇA! Bom trabalho, pessoal! ${ }^{10}$

O Laboratório continua desenvolvendo seus projetos para, cada vez mais, alcançar, como apontou D'Ambrosio, produções educacionais e artísticas transdisciplinares e transculturais.

\section{Referências}

BEHANCE. Drawing Narratives: from sand to light | 2016. Disponível em: < https://www.behance.net/ gallery/42248335/Drawing-Narratives-from-sand-tolight-2016 >. Acesso em: 23 nov. 2019.

\footnotetext{
10 Original: Do you know that Brazil currently doesn't have a ministry of culture, due to the politics of their current president? Can you believe it?! I can.

These guys came all the way long to Prague, without being supported by their state, to share culture, art and raising thoughts. Their work as a transdisciplinary laboratory of scenography, lead by Sonia Paiva is super. Why? Because they go beyond the visible and there is no violence, nor intruding in that. Anyone can do it.

I visited their workshop on PQ 2019 and left the space with a genuine thought, comparing my country's shitty politics towards culture with theirs: We are all the same. Can WE do it? No point of that question, just DO IT!

Great job, guys!

Comentário na página do Facebook do Laboratório Transdisciplinar de Cenografia. Disponível em:. < https://www.facebook. com/iff.atanasova/posts/10217673845211646 >. Acesso em: 17 nov. 2019.
}

BRASIL: LABirintos Compartilhados. Projeto Curatorial da Mostra das Escolas de Cenografia Brasileiras. Disponivel em: <https://brasillabirintoscompartilhados.files.wordpress.com/2014/05/projeto-curatorial. pdf $>$. Acesso em: 23 nov. 2019.

COHEN, Miriam Aby. O desenho da cena como experiência: intersecções na prática artística contemporânea entre cenografia instalação expografia. 2015. Tese (Doutorado em Teoria e Prática do Teatro), Escola de Comunicações e Artes, Universidade de São Paulo, São Paulo, 2015.

D’AMBRÓSIO, Ubiratan. Transdisciplinaridade. São Paulo: Palas Athena, 1997.

MORIN, Edgar. Os sete saberes necessários à educação do futuro. São Paulo: Cortez Editora, 2013.

MORIN, Edgar. Introdução ao pensamento complexo. Porto Alegre: Sulina, 2015.

MUNIZ, Rosane (Org.). Brasil: Tudo por Recomeçar: Quadrienal de Praga: Espaço e Design da Performance $=$ Everything to start over - Brazil: Prague Quadrennial of Performance Design and Space 2015. Rio de Janeiro: Funarte, 2015.

PAIVA, M. C. Sônia. A encenação pictórica: uma abordagem transdisciplinar. Dissertação (Mestrado em Arte). Universidade de Brasília, Brasília, 2006.

PAIVA, Sônia (Coord.). Brasil: LABirintos Compartilhados. Brasília: Universidade de Brasília, Laboratório Transdisciplinar de Cenografia, 2015.

PAIVA, M. C. Sônia. O Laboratório Transdisciplinar de Cenografia ( $L T C)$ : lócus do espaço e desenho da cena no Brasil. Tese (Doutorado em Artes), Universidade de Brasília, Brasília, 2016.

PAIVA, Sônia. Stage Design Transdisciplinary Laboratory (LTC): redesigning Brazil's Student Exhibit at PQ 2015. In: LOTKER, Sodja (Ed.). Transformations of Prague Quadrennial from 1999 to 2015. Published online in 2016. Disponível em < http://www. pq.cz/wp-content/uploads/2018/07/Transformation_ of_the_Prague_Quadrennial_from_1999_to_20152. $\overline{\text { pdf }}>$. Acesso em: 08 mar. 2020. 
VIANA, Fausto (Org.). Diário das escolas: cenografia PQ'11 - School diary: scenography PQ'11. Rio de Janeiro: Funarte, 2011.

Recebido: 30/08/2019

Aprovado: 24/03/2020 